\title{
The Secret Smiles of Things: Sartre's Realism Reconsidered
}

\author{
Simon Gusman ${ }^{1}$ (iD
}

Accepted: 22 July 2021 / Published online: 9 August 2021

(c) The Author(s) 2021

\begin{abstract}
In this article, I argue against a widespread misconception concerning the nature of things in Sartre's philosophy. Sartre's conception of the nature of things concerns the idea that outside of consciousness a single undifferentiated mass of brute being exists which is divided into definitive things by consciousness. I propose a different reading of Sartre's realism. Such a reading is based primarily on Nausea, Being and Nothingness and Consciousness of Self and Knowledge of Self states that, contra common conception, there is no brute being outside of consciousness, but rather, a vast multitude of different things.
\end{abstract}

Keywords Jean-Paul Sartre · Realism · Ontology · Things · Objects · Phenomenology

\section{Introduction}

The philosophical position of realism concerning things has become increasingly popular in recent decades. New forms of this strain of thought have emerged such as 'speculative realism' or the aptly named 'new realism' (Bryant et al. 2011). In light of this recent popularity, it is worth reinvestigating realist positions from the philosophical tradition. Although exact definitions of what realism entails vary from author to author, they all revolve around the idea that the things we experience exist in one form or another independent of our experience.

One such position is defended by Jean-Paul Sartre (Duncan 2005; McCulloch 1993). Many contemporary realists are critical towards phenomenologists like Sartre (Harman 2005; Sparrow 2014). Because of their focus on subjective experience, phenomenologists are thought to be unable to make claims about things outside of consciousness. Although we will not delve into the details of this criticism, it provides further motive to reconsider Sartre's phenomenological realism once more. Sartre's position takes subjective experience as its starting point but aims to

Simon Gusman

simon.gusman@ru.nl

1 Radboud University, Erasmusplein 16525 HT, Nijmegen, Netherlands 
subsequently move beyond conscious experience to things as they are in themselves. A widespread misconception concerning his position is that outside of consciousness a monolithic mass of brute being exists from which consciousness distils definitive objects. ${ }^{1}$ This position has a long-standing history in Sartre scholarship. An appeal to being as a mass can already be found in Jean Wahl's A Short History Of Existentialism, written in 1949 (Wahl 1949). A well-known example of this misreading can be found, for instance, in the translator's preface that preceded many older editions of Being and Nothingness. Translator Hazel Barnes presents Sartre's notion of being-in-itself, to which we will return in more detail in the third section of this article, as follows:

It is a fullness of existence, a plenitude which can not possibly isolate one part so as to contrast it with another, or posit a whole over against its parts, or conceive a "nothing" in opposition to which it is "everything." It is simply undifferentiated, meaningless massivity. Without consciousness therewould not be a world, mountains, rivers, tables, chairs, etc.; there would be only Being. In this sense there is no thing without consciousness, but there is not nothing. Consciousness causes there to be things because it is itself nothing. Only through consciousness is there differentiation, meaning, and plurality for Being. (Barnes 1978: xx)

More recently, the idea that being is a single mass has been proposed by Detmer (2008) and by Daigle (2010). Detmer's rendition is especially striking when it comes to the massiveness of being. Detmer compares being to a slab of stone from which consciousness sculpts different objects (Detmer 2008: 65).

In this article, I will show that this interpretation of Sartre's position is wrong and that instead of a single mass of being, there exists a vast multitude of things outside of consciousness, which consciousness only influences on the level of the meaning they have for us. This idea has been addressed briefly by Gardner (2009: 76f.). Apart from being rather brief, he focuses solely on the introduction of Being and Nothingness and only mentions his novel Nausea. Although I also discuss these two works at length, I provide more context by relating them to other texts and will discuss the latter in more detail. By addressing the issue throughout many of Sartre's works, I aim to show that the topic of the massiveness of being is not just related to a few paragraphs at the beginning of Being and Nothingness, but is a central part of Sartre's oeuvre.

This article is structured in the following manner. We will first turn to Sartre's exposition on the nature of things in Nausea. Specifically, we look in detail at the famous municipal park scene and relate this to remarks by Sartre in interviews, his War Diaries and by Simone De Beauvoir in her memoir The Prime of Life. Subsequently, we turn to Being and Nothingness. We will discuss the introduction of this work and explain his claims there by comparing them to other works, most importantly the often overlooked article Consciousness of Self and Knowledge of Self. By

\footnotetext{
1 The idea that there is a single monolithic mass of being outside of experience seems to correspond with Levinas idea of the \#il y a' (see Brogan 2001).
} 
doing this we will see how Sartre elaborates on the ideas found in Nausea in a more systematic manner.

\section{The Municipal Park}

In order the grasp the exposition of the nature of things independent from consciousness in Nausea, we will first see what Sartre's general position is with regards to realism in his early works. Nausea is, first and foremost, a novel. However, it is also regarded to be one of Sartre's most important philosophical treatises from before the Second World war. Although Sartre does not use the term realism often in this period, it can be considered one of the central themes of his philosophy. In The Transcendence of the Ego, he does say about phenomenology that "it has been centuries since philosophy has given evidence of such a realist trend. Phenomenologists have immersed man back in the world" (2004: 29). In later interviews, Sartre states multiply times that realism was his main philosophical interest at the time. For example, he describes his philosophical project to be "to provide a philosophical foundation for realism. Which in my opinion is possible today, and which I have tried to do all my life" (Sartre 1973: 36f.). In another interview, he says: "I would like to say that what was very important to me was realism, in other words, the idea that the world existed as I saw it and that the objects I perceived were real" (Sartre 1981: 10).

Although the phenomenological approach that permeates his early works is very much focused on subjective experience, Sartre thinks it is very important that these experiences are directed towards objects outside of consciousness. This is the principle of intentionality, which he takes from Husserl. ${ }^{2} \mathrm{He}$ regards this to be "the essential principle of phenomenology" (Sartre 2004: 6). This means that "All consciousness is consciousness of something," or in other words, that the object of consciousness is always something that exists outside of that experience (Sartre 1970: 5). In The Imagination, Sartre describes the idea in the following manner:

Intentionality-this is the essential structure of all consciousness. There naturally follows a radical distinction between consciousness and that of which there is consciousness. The object of consciousness whatever it is (save in the case of reflective consciousness) is in principle outside of consciousness; it is transcendent. (Sartre 2012: 127)

Sartre briefly discusses the evidence for the intentional structure of consciousness. The phenomenological method involves a phenomenological reduction that puts everything outside of consciousness in parentheses. This also includes our presuppositions about the world that we hold in ordinary life. This also includes 'spontaneous realism,' our ordinary practical belief that the things we encounter in the world genuinely exist outside of our experience of them (Sartre 2012: 125). It

\footnotetext{
2 Sartre would later come to realize that he was mistaken: "I took Husserl for a realist, which he is not" (Sartre 1973: 25).
} 
seems therefore that phenomenology is not realist at all, but that the reduction severs the ties between consciousness and the world. This is not the case however, as even after the phenomenological reduction the structure of consciousness remains so that each experience is directed towards an outside object. Hence, intentionality survives the phenomenological reduction. Every aspect of consciousness discovers after the reduction remains a part of the structure of consciousness once we return to the ordinary approach to things (Sartre 2012: 126). Therefore, Sartre considers this to be a proof for realism: "The phenomenologist, indeed, having put the world 'in parentheses,' has not lost it by doing so" (Sartre 2012: 136).

This is still a very meagre explanation of the 'proof' that objects exist independently of our experience of them. After all, the fact that consciousness has a structure as if it is directed at an object, does not really provide much evidence with regards to the existence of said object independent of our experience. Sartre will return to this topic in a much more elaborate fashion in Being and Nothingness, as we will discuss at great length in the next section.

For now, it is important to note that Sartre thinks that intentionality implies realism and hence the question arises concerning the exact nature of the things outside of consciousness. It is this question that Sartre answers in Nausea. In a 1965 interview, he states the aim of the novel is precisely to question the nature of things:

Heidegger was the only author the Germans allowed us. He argues that, in the last analysis, objects are utensils. In my first novel, Nausea, I looked at trees and tried to define just what they are by means of words, so as to get down to essences: in other words, I embarked on a perpetual questioning of things, of trying to ascertain what they are. (Sartre 1965: 70) ${ }^{3}$

The trees refer to the famous municipal park scene in Nausea. As Sartre tells us in the War Dairies, it is in this scene specifically that he wanted "to catch the secret smiles of things seen absolutely without men," pushing "to the point of dehumanizing entirely the secret of things" (Sartre, 1984, pp. 145-146). However, staying true to his phenomenological methodology, he admitted that one cannot start from the point of view of things:

I understood it was necessary to present meaning still adhering to things, since it's never entirely detached from them, and - in order to exhibit it - to show rapidly some of the objects that secrete it, and to make their equivalence felt[.] (Sartre, 1984: 145)

Thus, apart from being a captivating part of Nausea as a novel, the municipal park scene can also be understood as a philosophical treatise on things as they are apart from our experience, yet described from the limits of our experience. This experience of the limits of what we can experience is the mood from which the novel gets its name: nausea. The idea that certain fundamental moods allow us to experience fundamental aspects of reality stems from Heidegger, who analyses

\footnotetext{
3 Interestingly, contemporary realist Harman also departs from Heidegger's analysis of tools or utensils (Harman 2002).
} 
boredom and angst (Heidegger 1995: 59-168; 1996: 172-178). Sartre describes the mood of nausea as "the existential grasping of our facticity" (Sartre 1984: 133). Facticity, another term made famous by Heidegger, refers to the state of affairs of the world that precede our existence. For Sartre, this equates to things as they are without us experiencing them.

The aforementioned municipal park scene takes place near the end of the novel. Although the protagonist has experienced Nausea before, the most severe episode takes place when he is looking at the root of a chestnut tree:

So I was in the municipal park just now. The root of the chestnut tree plunged into the ground just underneath my bench. I no longer remembered that it was a root. Words had disappeared, and with them the meaning of things, the methods of using them, the landmarks which men have traced on their surface. I was sitting, slightly bent, my head bowed, alone in front of that black, knotty mass, which was utterly crude and frightened me. And then I had this revelation.

It took my breath away. Never, until these last few days, had I suspected what it meant to 'exist'. (Sartre 2000: 182)

Bare existence is revealed to the protagonist. In ordinary life, things always have a certain meaning for us. They appear within the frame of reference of our endeavours. In this situation, we are never explicitly aware of their existence: "usually existence hides itself. It is there, around us, in us, it is $u s$, you can't say a couple of words without speaking of it, but finally you can't touch it" (Sartre 2000: 182). The protagonist also relates this core idea to tools: "I picked them up in my hands, they served me as tools, I foresaw their resistance. But all that happened on the surface" (Sartre 2000: 183). As long as things have a meaning to us, we can use them for our own ends. They appear as tools. Even things that are currently uninteresting for us appear to us as background, with the meaning of currently being of no interest to us attached to them.

We need to have a specific kind of experience for things to lose their meaning for us. It is unclear how and why such an experience happens. Sartre himself is not clear on the question of whether he himself has had such an experience. On the one hand, he writes in the War Diaries that he has never had an experience of Nausea (Sartre 1984: 62). On the other hand, in a later interview, he says that he did in fact experience Nausea, and connects it to his encounter with mescaline (Gerassi 2009: 79-81). This experience is described in some detail by Simone de Beauvoir in her memoir, The Prime of Life:

He [Sartre] had not exactly had hallucinations, but the objects he looked at changed their appearance in the most horrifying manner: umbrellas had become vultures, shoes turned into skeletons, and faces acquired monstrous characteristics, while behind him, just past the corner of his eye, swarmed crabs and polyps and grimacing Things. (De Beauvoir 1965: 209)

It is telling that De Beauvoir capitalizes the word "Things" which hints towards the theme of the municipal park scene. Once things have lost their meaning, they 
are nothing more than precisely that: Things. She goes on to describe the effect the substance had on Sartre's mood and perception:

For several days he had been in a state of deep depression, and the moods that came upon him recalled those that had been induced by mescalin. This frightened him. His visual faculties became distorted: houses had leering faces, all eyes and jaws, and he couldn't help looking at every clockface he passed, expecting it to display the features of an owl - which it always did. He knew perfectly well that such objects were in fact houses and clocks, and no one could say that he believed in their eyes and gaping maws - but a time might well come when he would believe in them; one day he could really be convinced that there was a lobster trotting along behind him. (De Beauvoir 1965: 210)

The aftermath of the mescalin caused Sartre to see certain qualities in objects which the objects did not possess. Although he was afraid of losing his touch with reality altogether, it is important to note that he did not do so. He always stayed aware of the fact that the things he experienced were the things he would normally encounter in the world around him. It is just that the way they appeared to him had changed: the clock appears as having owllike features but is still the same thing which appears differently. It seems therefore that there is still meaning attached to it, albeit a different one that we would ordinarily perceive. It still relates to the experience of Nausea however: things can appear to us in very different ways, with very different meanings. In Nausea, the protagonist describes the things he sees in the park as "Strange pictures. They represented a host of things. Not real things, other things which look like them" (Sartre 2000: 191). Nevertheless, there is something that underlies these meanings and makes them the same thing throughout these shifting ways of appearing: their existence.

The idea that we can have an experience of how things are when we do not experience them, i.e., their bare existence, may sound contradictory. This is why Sartre stresses in the above quote that meaning can never be truly detached from object. We can merely experience the limits of the meaningful world and thereby know that there is something ungraspable about things: "the world of explanations and reasons is not that of existence" (Sartre 2000: 185). Therefore, it is also difficult to put the experience into words. In Nausea, the protagonist explains the experience by saying "I was thinking without words, about things, with things" and "I am struggling against words" (Sartre 2000: 185). As the novel is written in the form of a diary, the protagonist first has the experience of Nausea and with it a certain clarity described as 'the key to Existence,' but struggles to adequately define it afterwards (Sartre 2000: 185). Words are a prime example of something we use to constitute meaning and as Nausea is an experience of the limit of meaning, it is difficult to describe. What remains when meaning is peeled away, is something monstrous:

It [existence] had lost its harmless appearance as an abstract category: it was the very stuff of things, that root was steeped into existence. Or rather the root, the park gates, the bench, the sparse grass on the lawn, all that had vanished; the diversity of things, their individuality, were only an appearance, a veneer. 
This veneer had melted, leaving soft, monstrous masses, in disorder - naked, with a frightening, obscene nakedness. (Sartre 2000: 183)

This passage is one of the most central in the scene because it is what gives rise to the common misinterpretation we have discussed in the introduction: Sartre clearly states that the diversity and individuality only exist on the level of meaning and not on the level of things as they truly are. This is true in a certain sense, however, it goes too far to say that because diversity and individuality are only an appearance, what remains is a single massive being. First and foremost, this is what is clearly stated in the sentence that follows the statement about diversity and individuality. It states that there are "masses, in disorder". Masses is clearly plural, suggesting masses of beings rather than a single being. These masses are in disorder, which also excludes that it is a single being. How can a single being be in disorder? This implies that there are multiple things that were somehow ordinarily related to one another, and have lost this relationship to each other. They do not magically merge into a single being, they simply lose the relations that we consider meaningful that they have with regard to each other.

Second, Sartre means something specific with diversity and individuality. These concepts are somewhat underdeveloped in Nausea, but will be elaborated upon in Being and Nothingness, which we will discuss in the next section. Individuality has to do with demarcation and this, in turn, has to do with nothingness, rather than being. When we isolate a certain individual being from another one, we say that one thing has a certain meaning and certain qualities and is therefore not another thing. These clear-cut distinctions have to do with the meaning of things. This is best illustrated by what is said in Nausea about movement:

I said to myself, as I followed the swaying of the branches: 'Movements never quite exist, they are transitions, intermediaries between two existences, unaccented beats.' I got ready to see them come out of nothingness, gradually ripen, blossom: at last I was going to surprise existence in the process of being born.

I took only three seconds to dash all my hopes to the ground. In those hesitant branches which were groping about like blind men, I failed to distinguish any 'transition' to existence. The idea of transition was another invention of man. [...] Admittedly a movement was something different from a tree. But it was still an absolute. A thing. (Sartre 2000: 189f.)

We can only distinguish between a thing and a movement that thing makes in light of our conceptual apparatus. For example, that a branch was first in one place and now in another, is a judgment that involves nothingness as the branch is no longer in its previous place. Therefore, any form of transition only exists on the level of our judgments. It is, as the protagonist says, another invention of man. This means that things exist timelessly. A being may appear for the first time in our experience, but that does not mean however that it comes out of nothingness. Although this might seem counterintuitive, we could think of examples where it is indeed a matter of meaning whether they cease to exist or not. One could think of collective beings, such as nations or companies, which seem to have perished may be re-founded. Is 
the re-founded being a new being or the same being? Did it exist in the period of inactivity? Sartre would say that it always existed. This is not only the case for cultural entities of which it may be said that meaning plays a bigger role, but for all things. Qua existence, they just exist, regardless of the role they currently play in our experiential world. Thus, there is no nothingness that is unrelated to consciousness, outside of us there are only beings.

This appeal to nothingness relates to all individuality. When we make rigid distinctions between things, we say that something is this thing, and therefore not that other thing. An example of this conceptual individuality are borders: Imagine a forest that gradually turns into a mountainous area with fewer trees. We may draw a line somewhere where we decide that the forest ends and the mountains begin. That kind of rigid individuality exists only on the level of meaning. On the level of being, there is the area as a whole: the forests, the mountains, the border area, the trees, the rocks, etc. Certain borders between those things may be highlighted by the meaning we impose upon them but they continually move and slide into each other. Outside of us are 'swarms of existences' (Sartre 2000: 190). The fact that individual beings can be discerned from each other in a vast amount of ways does not mean that they are a single entity.

This brings us to the point of diversity. Each thing is different from another but that does not mean that they belong to fundamentally different categories. Each thing is qua existence the same. Therefore, we cannot distinguish the being of a tree from that of a root, a park, a branch or of a movement of a branch. ${ }^{4}$ Ontologically there is no difference between them. The statement that "a movement is not a thing, but something that a thing does" would be a conceptual statement of diversity. Again, these kinds of ways in which we differ certain kinds of beings from other beings, branches from movements, only exist on the level of meaning.

Hence, everything is an absolute. Just like things always escape the meanings we assign to them, they are also irreducible to any relationship they have to other things. This brings us to the central notion concerning being in Nausea, superfluousness:

Superfluous: that was the only connection I could establish between those trees, those gates, those pebbles. It was in vain that I tried to count the chestnut trees, to situate them in relation to the Velleda, to compare their height with the height of the plane trees: each of them escaped from the relationship in which I tried to enclose it, isolated itself, overflowed. I was aware of the arbitrary nature of these relationships, which I insisted on maintaining in order to delay the collapse of the human world of measures, of quantities, of

\footnotetext{
${ }^{4}$ We can compare this idea to that of contemporary new realist Markus Gabriel, who in turn attributes it to Frege: "there may be a grove in a forest, or there might simply be five individual trees that are part of the forest. The same thing can be a grove (one sense) or five trees (another sense). Depending on the field of sense, the same thing is a hand, a whirl of atoms, a work of art, or a tool. And the five trees are a grove or individual trees (or again: another whirl of atoms)" (Gabriel 2015: 69). The field of sense is the framework that determines meaning and therefore which configuration is primary. There is however no all-encompassing field of sense that can say which field of sense is more true than others. Hence, all things exist.
} 
hearings; they no longer had any grip on things. Superfluous, the chestnut tree, over there, opposite me, a little to the left. Superfluous, the Velleda.... (Sartre 2000: 184)

Sartre's notion of superfluousness means that every thing 'overflows' itself. This means that it is always more than any relationship towards another thing. The French de trop can also be translated as 'too much,' meaning that it is always more than whatever relationships it may have. This is, for example, true for the fact that it cannot be reduced to the relationship we have with it. If this were the case, there would be no things outside of our experience. As we have discussed, things also cannot be reduced to the meanings we impose upon them, including those that have to do with individuality and diversity on a conceptual level. We can never fully grasp them and know all there is to know about them and compile a definite list of characteristics. In other words, there is a certain experiential inexhaustibility to them. We will return to this topic in the next section. For now, it suffices to say that in this inexhaustibility, we also see, yet again, that Nausea is an experience of limitation: we experience that we can never fully grasp everything about a thing. This also relates back to Sartre's encounter with mescalin: a clock may suddenly appear as an owl. Each thing has a hidden depth.

The lack of diversity also resonates with the fact that things do not only overflow the relationship they have to us, they also overflow the relationship they have to each other. Therefore, they exist in isolation. They can neither be reduced to their parts nor to a larger whole, as we have already discussed in the example of parks, trees, branches, roots, etc. The relationships are always contingent and never necessary. Although the way in which every thing exists is always the same, namely as this pocket of superfluousness, there is not a single being to which they can be reduced. The monolithic conception of being contradicts the very notion of superfluousness. If a thing overflows all relationships, it cannot be reduced to a single mass of Being. That would contradict Sartre's reasoning altogether. The swarm of things outside of us is not a single being, each thing exists in isolation. In their isolation, each thing exists in the exact same way. Thus, all things have an ungraspable ground of being, which is an entirely different position than the idea that all things have the same ungraspable ground of being.

We have now reached the end of our discussion of Sartre's realism as he presents it in Nausea. An experience of the titular mood leads the protagonist to encounter the existence of things as they are beyond the meaning we normally impose upon them. When these meanings are gone, only an endless swarm of things remains which can only be defined by their superfluousness: the fact that they overflow every relation they have, including that to us and to other things.

\section{Being-in-itself and the 'this'}

Sartre's exposition of the superfluousness of things found in the municipal park scene in Nausea gives us the foundation for his realism. The experience of nausea is however far from ordinary and the literary style in which it is described makes 
it difficult to grasp all the philosophical implications. In Nausea, the protagonist exclaims that: "Existence is not something which allows itself to be thought of from a distance; it has to invade you suddenly" (Sartre 2000: 189). We do, however, find a more systematic exposition in later writings. It can be found primarily in the introduction to Being and Nothingness and we find another description in the article "Consciousness of Self and Knowledge of Self". Apart from these philosophical treatises, we also find the position described in a nutshell in "What is Literature?":

Each of our perceptions is accompanied by the consciousness that human reality is a 'revealer', that is, it is through human reality that 'there is' being, or, to put it differently, that man is the means by which things are manifested. It is our presence in the world which multiplies relations. It is we who set up a relationship between this tree and that bit of sky. Thanks to us, that star which has been dead for millennia, that quarter moon, and that dark river are disclosed in the unity of a landscape. It is the speed of our car and our aeroplane which organizes the great masses of the earth. With each of our acts, the world reveals to us a new face. But, if we know that we are directors of being, we also know that we are not its producers. If we turn away from this landscape, it will sink back into its dark permanence. At least, it will sink back; there is no one mad enough to think that it is going to be annihilated. It is we who shall be annihilated, and the earth will remain in its lethargy until another consciousness comes along to awaken it. Thus, to our inner certainty of being 'revealers' is added that of being inessential in relation to the thing revealed. (Sartre 1988: 48).

Here, Sartre gives a more concise description of the ideas already present in Nausea. The meaningful world which we experience only exists in interaction between us and the world. Although we are what Sartre calls the 'directors of being,' we are not its producers. Sartre deems a non-realist position to be absurd. Although things can show their different faces because of our presence, there is still a thing required outside of our experience which can reveal itself. Furthermore, Sartre once again stresses that the relationships between things are inessential to them: they are imposed upon them by us. This once again stresses that every thing exists on its own and overflows definite characteristics and relationships.

Before we turn to Being and Nothingness, it is important to note that when Sartre uses the term realism in this work, he refers to representational realism. This is the epistemological position that when we experience things, we do so via representations of these things in our consciousness. Sartre is very much opposed to this position and defends the idea that we experience the things themselves. In a letter to De Beauvoir, Sartre calls his position 'an absolute neo-realism' (Sartre 1993: 43).

With this in mind, let us turn to the introduction of Being and Nothingness. The introduction of this work immediately starts from the phenomenological principle of appearing, 'the phenomenon'. This seems to be another phrasing of the idea of intentionality (Sartre 2018: 22). It seems that he considers this idea to be simply true and adequately developed by his predecessors. He takes it as his axiom for the ontological system he starts out to develop in Being and Nothingness. Sartre aims to find the ontological consequences of the idea that we directly experience the things 
outside of our own consciousness. In what manner can we say that things exist and that which experiences these things, consciousness, exists? We will not delve into the details concerning the latter. It suffices to say that Sartre deduces two absolute modes of being from the phenomenon. The being-for-itself of consciousness, and the being-in-itself of things. As we are primarily interested in the question of how things exist outside of consciousness, we will focus on the latter.

The phenomenon eliminates a number of dualisms that appear throughout the philosophical tradition. An important one is the Kantian duality between the thing as it appears and the being behind the appearance:

The phenomenon remains relative because its 'appearing' necessarily implies someone to whom it appears. [...] It does not indicate, behind its shoulder some true being, a being that is itself the absolute. It is what it is absolutely, because it is disclosed as it is. (Sartre 2018: 2)

The idea of intentionality simply implies that the object of consciousness (save for the case of reflection) is given in our experience. That does mean that there is no true being hidden behind the experience, but it does not adequately answer the question concerning the being of this thing. What is its mode of being? In order to answer this question, Sartre turns to a new kind of dualism, that between 'the finite and the infinite' (Sartre 2018: 4). Although the phenomenon is an appearance of a thing, it never reveals itself fully. In the case of visual perception, we quite literally only see one side of a thing and have to walk around it to see the other side. Things can always be revealed to us in a different light, literally and figuratively. The ways in which an object can manifest itself is infinite: although a thing may appear in a way that is almost identical to which it has appeared before, it will be accompanied by a feeling of familiarity and will therefore have a different meaning to us. As we already mentioned in the previous section when we mentioned the inexhaustibility of things: things can never be exhausted, we can never experience everything there is to experience about them. This is what the distinction between the finite and infinite refers to: an appearance of a thing is always finite, but the ways in which it could appear is infinite.

This is in turn only possible because the series of appearances is 'connected by a principle that does not depend on my whim' (Sartre 2018: 4). The fact that the multiple appearances of a thing are indeed appearances of the same thing cannot be attributed to consciousness. When I walk around something and see it from multiple angles, it is given in the experience that it is the same object. The principle of the series of appearances of a thing is what Sartre calls an essence. This essence, however, is also not something that is somehow behind the series: "an essence, understood as the principle of a series, is no more than the connection between appearances - which means it is itself an appearance" (Sartre 2018: 3). This point is important. Although the essence is the principle that ties all the appearances of a series together, it is itself something that can appear to us, for example when we actively think about the fact that the tree we saw yesterday is the same one we see today. Therefore, the question of the being of the appearance is not yet answered, we still need to account for the being of the essence. In other words, the essence is the principle of the series, but we still need to account for 
the existence of the series as a whole. Sartre describes the distinction between essence and being in Consciousness of Self and Knowledge of Self:

[I]t is very evident that the essence does not exist with regard to the object in the way that being does with regard to the phenomenon. Indeed, essence is the ground of the series of appearances of the phenomenon. Essence is that which permits me to join synthetically - the fact that, when I open this book, I see characters in it, the fact that when I pick it up, it has weight, the fact that if I burn it, it gives off smoke-all this must be reunited synthetically by the synthetic connection of the appearances: that is what I shall call the essence. (Sartre 1967: 120)

This description of the essence of an object is clear: it is that which makes us able to join certain appearances of the same object together as appearances of that object. As said, this is given in experience. When I hold a book in my hand, feel its weight and see the words written in it, it is given in the experience that both appearances are of the same book. This is quite different for being, which never reveals itself. Sartre immediately continues his description of the difference between essence and being:

On the contrary, when it's a question of the contrary of being, one maintains that being accompanies all the appearances of an object. It is not different in each of these appearances. The appearance does not disguise it, no more does it reveal it. If I cut this book into little pieces, if the fancy takes me, there will be as much being in each of the pieces as in the book. When I give it another form by burning it or in compiling from it, it will always have as much being in each of its manifestations. A division to infinity or a transformation will not reveal the book to me in a better way, nor will it hide it from me. (Sartre 1967: 120)

Here, the fundamental difference between essence and being is described by Sartre. The essence is what binds the appearances of a series together, but that does not reveal anything about the being of theses appearances. We are here also reminded of the swarm of things: a book may be the same book when it is torn to pieces, but each piece is itself also an object. All these objects have an essence that binds them together. All these things are given to us as existing, but the being of them does not itself appear. However, it is also not disguised in the sense that there is somehow a being behind the object. Being can never appear because it is that which makes objects able to appear:

The being is something which I cannot grasp in its being, except as a phenomenon originating from the object which is presented. Being is that which makes the object appear. Each object is on a foundation of being. Each appearance has a being. But the being cannot in any case be reduced to appearance. (Sartre 1967: 120)

This means that there is nothing behind the series of appearances which supports its being. Thus, we must instead search for its 'transphenomenal foundation' 
(Sartre 2018: 7). In the introduction of Being and Nothingness, Sartre discusses two of those transphenomenal foundations. One of them is the being of consciousness, the for-itself and the other one is the being of things, the in-itself. In short, a phenomenon requires something to which it appears, consciousness, and something which appears, a thing. Again, we will not go into the details considering the for-itself here. It suffices to say that Sartre's argument is rooted in his account of intentionality. Intentionality according to him means that consciousness is nothing but a relationship to a thing and can therefore not exist on its own. Therefore, the for-itself depends on the in-itself:

Consciousness is consciousness of something: therefore transcendence is a constitutive structure of consciousness, which is to say that consciousness is born bearing on a being that it is not. Let us call this the ontological proof. [...] Naturally, this being is nothing other than the transphenomenal being of phenomena and not a noumenal being hiding behind them. Consciousness implies the being of this table, of this package of tobacco, of the lamp and more generally, the being of the world. Consciousness requires simply that the being of that which appears does not exist only in so far as it appears. (Sartre 2018: 22f.).

Here, we see once again that the transphenomenal being is not a general monolithic mass of being, with Sartre stressing the being of each individual object around him. This would be a noumenal being hiding behind the objects. Instead, he clearly states that all things that appear to consciousness have a transphenomenal dimension to them. However, as the being is transphenomenal, literally 'beyond appearing,' we cannot describe it as one would describe a thing. We can, however, deduce its meaning (Sartre 2018: 24). Although Sartre uses the term meaning here, it still seems to be in continuation with the experience of Nausea: we can experience the limits of experience and being can reveal itself, but because being is that which escapes our conceptual apparatus, it remains impossible to describe it in full. This does not mean however that we cannot give a general description of characteristics that it should have.

In this context, Sartre also seems to distance himself a little from Nausea, when he says that in order to give a phenomenological account of being, that "Being will be disclosed to us through some immediate means of access (boredom, nausea, etc.)" (Sartre 2018: 6). This description will only give an account of the phenomenon of being, which as it is itself a phenomenon, does not answer the question of the being of phenomena. One must still pose the question of the being of the phenomenon of being. Hence, the description Sartre gave in Nausea is not wrong per se, as Sartre still thinks that being can disclose itself in special experiences. However, in the context of ontological inquiry, this is not enough to constitute evidence for the nature of being outside of our experience.

Sartre gives three characteristics of being-in-itself: being is itself, being is what it is, and being is (Sartre 2018: 29). These characteristics are indeed very general and may sound similar and perhaps even obvious, but Sartre tries to convey something quite nuanced. The first one, 'being is itself,' means that it is not rooted in something else (Sartre 2018: 26). It is truly an absolute, because if another being would support 
it, then this being would require another being to support it. We have already discussed this at length: there is nothing behind the being of things.

The second characteristic, 'being is what it is,' means that it has no relationships within itself. Another way to say this is that it completely coincides with itself. This characteristic easily falls prey to the monolithic misinterpretation of being-in-itself, for Sartre describes it as 'massive' (Sartre 2018: 28). It is important to note that the English word massive and the French word massif have similar meanings but also different connotations. Both have to do with mass and size, but the French word can also mean solid in the sense of an object consisting of only one kind of material. For example, in the sense that we speak about a solid, wooden chair. It is this meaning that Sartre is tending to: being-in-itself is solid. This is also how the word is translated in the older translation of Being and Nothingness by Hazel Barnes. Sartre does not mean this in the material sense, but in the sense that it has no different components or parts in any sense. This characteristic follows the same logic as the first one: if being-in-itself consisted of parts, then these parts needed to exist in some way and hence we would have to answer the question concerning their being once again. Therefore, it is solidly being and nothing else. Sartre also calls this the opacity of being and states that "Being-in-itself has no inside that could be opposed to and outside" (Sartre 2018: 28).

Another important aspect of the second characteristic is that "the in-itself has no secret" (Sartre 2018: 28). This formulation seems strange in regard to the idea that being is superfluous and inexhaustible. It seems that Sartre says that being is shrouded in secrecy. We can in principle never know anything about a thing and hence it always seems to have secret aspects to us. This is true, a specific being always has secrets to us, but it is not its being that is secret. In other words, although to exist in-itself means that a thing is inexhaustible by our experience of it, we have discovered that this $i s$ the way in which it exists. This mode of existence of being superfluous has no further secrets when it comes to its being. To put it simply: it is no secret that every thing exists in such a way that it has secret aspects to us. These secrets aspects, however, are not a part of its mode of being, as being-in-itself is solidly being.

Furthermore, this opacity relates to the relationship between different beings. Sartre states that "being is isolated in its being, and maintains no relationship with anything else" (Sartre 2018: 28). Again, we must understand this in the sense that the being of each thing has no relationship to itself or other things. The fact that a book consists of pages does not mean that the being of the book depends on the being of the pages. The book may rest on a shelf, but the being of the book does not rest on the being of the shelf. Each exists in isolation in this regard.

This is very much in line with Nausea and the example of the swarm of things: relationships between things and also between perceived parts of those things have to do with our conceptual demarcations. Being is 'full positivity,' and does allow for any demarcations which imply negativity (Sartre 2018: 28). This is addressed again by Sartre much later in the book, in a section called 'On Determination as Negation' (Sartre 2018: 255). Here he states that "its [the for-itself] presence is what makes it the case that there is a 'this one' rather than a 'that one"' (Sartre 2018: 255). It is the presence of consciousness that allows for negativity. Sartre adds to this that totality 
is also something that can only come to being through consciousness. The judgment that "this is everything that exists" implies that someone accounted for all beings and judged that there is nothing beside those beings. A totality of beings is not the same as the endless plurality of beings. Hence: "the for-itself can make it the case that there is an all, and that there are 'thises"' (Sartre 2018: 256):

Indeed, we should be quite clear that we can only refer to this being right

here as 'this' against the ground of the presence of all being. It does not follow that, in order to exist, one being needs all of being. (Sartre 2018: 256)

Sartre cannot be more clear: there is no such thing as a pure monolithic being that encompasses all things outside of our experience. In short, being does not allow for negativity as this would cause it to have parts and therefore internal relationships, but it does not follow that there is a single being that encompasses everything as this would also require negativity. Sartre states that we should not "understand being as one undifferentiated self-affirmation" (Sartre 2018: 27).

The third characteristic is that being is. This aspect has to do with necessity: every thing exists without reason. If this would be the case, the being would depend upon said reason, and hence would no longer be absolute. We would then have to ask the question concerning the being of the reason. This means that being is fully contingent: it simply is. It is therefore also beyond possible and impossible. This would require actual beings being derived from possible being, and would therefore again diminish its status of an absolute. Sartre describes this by using a familiar term:

Being-in-itself is never either possible or impossible; it is. Consciousness expresses this by saying - in anthropomorphic terms - that it is superfluous, which is to say that it is absolutely unable to derive it from anything, either from another being, or from something possible, or from a necessary law. Uncreated, without any reason for being or any relationship with another being, being-in-itself is superfluous for eternity. (Sartre 2018: 28f.)

Being is superfluous, it 'overflows' any relationship towards something else and every reason or explanation we try to give of it. Every attempt to fully capture it is doomed to fail. It is superfluous for all time. This means on the one hand that we will in principle never discover some reason behind it, some grand theory that finally makes us able to truly move beyond the limits of experience.

On the other hand, it also refers to the fact that being is beyond temporality. Change requires a negative judgment, something was first this and is now that. Such as judgment requires consciousness. However, as is the case with totality, we should not understand this to mean that things are in a certain way and are static and unchangeable. Staying the same also requires a certain negative judgment. First there was this moment, in which a thing has certain characteristics, and now that moment is no longer but the thing still has those characteristics. Such judgments also require negativity, and being, devoid of any negativity, is thus beyond temporality.

We may say that an acorn has become a tree and is therefore the same thing which changed. We may also say that an acorn is a different thing from the tree. 
Things swarm and flow into one another, regardless of our judgments. ${ }^{5}$ However, what does not change is the way in which they exist. Whether the acorn is the same thing as the tree or not, in any case, they still exist as a superfluous being. Being-in-itself is their mode of being. Each thing exists in this way, there is no ontological differentiation between their modes of being. ${ }^{6}$ This is, however, a very different philosophical position from that which regards that being to be a single thing.

The fact that Sartre ends the introduction with the description of these three general characteristics of being-in-itself is something which may contribute to the misreading that being-in-itself is a single, monolithic being. We must not forget the reasoning that leads Sartre to these characteristics, however. Sartre takes the phenomenon as a starting point, which leads him to the distinction between the finite appearances of things and the infinite series of those appearances. There needs to be something that binds the series together, a principle that causes all the appearances of an object to appear as being the same object. This cannot be the essence, because this is itself an appearance. The thing that appears needs to have a transphenomenal ground. This cannot be another object behind the thing as it appears, however, as this would mean that we simply introduce a new kind of thing and have to answer the question what the mode of being of this thing is. This would simply move the question of being, rather than answer it. Hence, there is no being behind the object, things as they appear do so on a ground of being. This being is transphenomenal and not itself a thing, that is to say, it is simply its mode of being.

This is itself an argument for the fact that there is no single being-in-itself. Sartre's argument rests on the principle that binds the series of appearances together, and hence every series needs to exist in-itself. Furthermore, Sartre's emphasis on the fact that the being of each thing is not itself a thing provides further reason to assume that there is no single in-itself. This monolithic being would be something different than the thing in question. Being-in-itself cannot be something, as it is a mode of being.

Sartre's idea that a thing as it appears cannot be reduced to another being behind it, brings us to the main tenet of Sartre's reasoning. This reasoning, at its core, resides in the strong emphasis on the irreducibility of being. Things cannot be reduced to another being and therefore exist separately, yet on the ground of the same kind of mode of being. This irreducibility of the being of things is precisely why being-itself is a transphenomenal foundation of Sartre's ontological system. It

\footnotetext{
5 This is reminiscent of Sartre's discussion of viscosity in the final pages of Being and Nothingness. Here, he attempts a 'psychoanalysis of things' (Sartre 2018: 777). He attempts to show what the way things appear to us can learn us about ourselves. In doing so, he also makes some ontological observations. The passage is notoriously dense and it seems that he could have taken any quality of things as a leading example, but he chose viscosity because it resembles the in-itself: "the viscous is the in-itself's revenge" and it is "a substance that is sticky, compromising and lacks equilibrium" (Sartre 2018: 789f.).

${ }^{6}$ It should be noted that although there is only one mode of being specific to things, there are in total three modes of being: the being of things, the being of consciousness, and the being of others. This elucidates the notion of a mode of being. There is no single consciousness, but each conscious experience has the mode of being for-itself and each person also exists as being for-the-other.
} 
cannot be reduced to anything else and we therefore need to assume that this is the way things exist.

The three characteristics also boil down to irreducibility: it cannot be reduced to something behind it, it cannot be reduced to any kind of component in it, and it cannot be reduced to any other kind of being. While Sartre only used the term superfluous for the last characteristic, we can transpose this term to all of them. To be irreducible means to escape all relations to other things, and this is precisely how Sartre uses the term superfluous in Nausea: Things overflow their relations, they are hence irreducible to them and each of them therefore properly exists in-itself.

Thus, for our purposes, it follows that each thing cannot be reduced to a single being-in-itself. Each thing exists as in-itself, meaning that its very mode of being is that it is irreducible to anything else. From this irreducibility or superfluousness it follows that each being cannot be reduced to a single being-in-itself. The description of the in-itself in the introduction of Being and Nothingness therefore further shows that Sartre is indeed a realist in the sense that things exist as things outside of our experience of them.

\section{Conclusion}

Our main aim is to show that in Sartre's realism, all things exist independently from each other and that there is therefore no monolithic mass of being outside of human experience. He addresses this theme in Nausea and in Being and Nothingness.

In the former he gives a literary description of an overwhelming experience of the titular mood of nausea, in which things lose the meaning they ordinarily have. When we reach this limit of our experience, a swarm of beings remain which are ungraspable by our conceptual schemas. They cannot be reduced to our experience and explanations, but from this also follows that they cannot be reduced to each other. They are superfluous, they continually overflow every attempt at reducing them to something else and therefore exist in isolation to each other.

In Being and Nothingness Sartre arrives at a similar conclusion, but does so by very different means. Instead of describing it experientially, he carefully dissects the notion of the phenomenon to arrive at the transphenomenal foundation of things: being-in-itself. This mode of being also means that things always escape us. They are inexhaustible by experience, irreducible to other beings and thereby also superfluous. This very superfluousness contradicts the common misreading of Sartre in which being-in-itself is interpreted as a single formless blob of being. Rather, we have shown that this is the mode of being of every single thing, rather than a single thing itself.

Where does this leave Sartre when it comes to contemporary debates concerning realism? As said in the introduction, many contemporary realists are critical towards phenomenology. Harman, for example, thinks that true realism must also account for how things interact outside of human interference: "In phenomenology, there is no relation between objects. But in our time the bar for 'realism' has been set so low that fans of almost any author can claim realism on behalf of their heroes" (Harman 
2011: 139). ${ }^{7}$ It seems that for Sartre, there is no true relation between things, as they exist in isolation and overflow every relation they could have to each other. However, Harman himself adheres to a similar view, in which things also exist in isolation, which he describes by saying that they withdraw from all relations: "the withdrawal of objects is not some cognitive trauma that afflicts only humans and a few smart animals, but expresses the permanent inadequacy of any relation" (Harman 2011: 44). Although their methods may differ, this notion of withdrawal seems to be very similar to the notion of superfluousness Sartre describes.

Whether Sartre's attempt at a phenomenological realism is convincing to those realists who are critical towards phenomenology remains to be seen. Because this method of philosophical inquiry takes our experience as a starting point, it can never fully move beyond it and account for things as they are outside of experience. This is however precisely what Sartre attempts: he aims to uncover the 'secret smiles of things'. Indeed, he does so by taking our experience as a starting point, but he aims to show the limits of experience and carefully shows that there must be something beyond experience. That which exists beyond consciousness is not something entirely ungraspable, but something which he carefully speculates about and comes to the conclusion that is indeed a plurality of superfluous things.

Open Access This article is licensed under a Creative Commons Attribution 4.0 International License, which permits use, sharing, adaptation, distribution and reproduction in any medium or format, as long as you give appropriate credit to the original author(s) and the source, provide a link to the Creative Commons licence, and indicate if changes were made. The images or other third party material in this article are included in the article's Creative Commons licence, unless indicated otherwise in a credit line to the material. If material is not included in the article's Creative Commons licence and your intended use is not permitted by statutory regulation or exceeds the permitted use, you will need to obtain permission directly from the copyright holder. To view a copy of this licence, visit http://creativecommons.org/licen ses/by/4.0/.

\section{References}

Barnes, H. (1978). Translator's Introduction. J.P. Sartre, Being and nothingness. Pocket Books, ix-lii.

Brogan, M. J. (2001). Nausea and the experience of the "il y a": Sartre and Levinas on brute existence. Philosophy Today, 45, 144-153.

Bryant, L., Srnicek, N., \& Harman, G. (2011). The speculative turn: Continental materialism and realism. Re.press.

Daigle, C. (2010). Jean-Paul Sartre. Routledge.

De Beauvoir, S. (1965). The prime of life. Penguin Books.

Detmer, D. (2008). Sartre explained: From bad faith to authenticity. Open Court.

Duncan, J. (2005). Sartre and realism-all-the-way-down. Sartre Studies International, 11, 91-113.

Gabriel, M. (2015). Why the world does not exist. Polity Press.

Harman, G. (2002). Tool-Being: Heidegger and the metaphysics of objects. Open Court.

Harman, G. (2005). Guerrilla metaphysics: Phenomenology and the carpentry of things. Open Court.

Harman, G. (2011). Quadruple object. Zero Books.

Heidegger, M. (1995). The fundamental concepts of metaphysics: World, finitude, solitude. Indiana University Press.

\footnotetext{
7 For a comparison between Harman and Sartre's theory of objects from the later works The Critique of Dialectical Reason (see Kleinherenbrink and Gusman: 2018).
} 
Heidegger, M. (1996). Being and time. SUNY Press.

Gardner, S. (2009). Sartre's "Being and nothingness": A reader's guide. Continuum.

Gerassi, J. (2009). Talking with Sartre: Conversations and debates. Yale University Press.

Kleinherbrink, A., \& Gusman, S. (2018). The Ontology of social objects: Harman's immaterialism and Sartre's Practico-Inert. Open Philosophy, 1(1), 79-93.

McCulloch, G. (1993). Sartre: Between realism and idealism? International Journal of Philosophical Studies, 1(2), 286-301.

Sartre, J. P. (1965). Playboy Interview: Jean-Paul Sartre: A candid conversation with the charismatic fountainhead of existentialism and rejector of the Nobel Prize. Playboy, 12(5), 69-76.

Sartre, J. P. (1967). Consciousness of self and knowledge of self. In N. Lawrence \& D. O'Connor (Eds.), Readings in existential phenomenology (pp 113-142). Prentice-Hall.

Sartre, J. P. (1970). Intentionality: A fundamental idea of Husserl's phenomenology. Journal of the British Society for Phenomenology, 1(2), 4-5.

Sartre, J. P. (1973). The itinerary of a thought. In Between existentialism and marxism (pp 33-64). London: Verso.

Sartre, J.P. (1981). The Interview. In P.A. Schilpp (Ed.), The philosophy of Jean-Paul Sartre (pp 5-51). Open Court.

Sartre, J. P. (1984). War diaries: Notebooks from a phoney war, November 1939-March 1940. Verso.

Sartre, J. P. (Ed.). (1988). What is literature?. In “What Is literature?” And other essays (pp 21-245). Harvard University Press.

Sartre, J. P. (1993). Quiet moments in a war: The letters of Jean-Paul Sartre to Simone de Beauvoir, 1940-63. Simon \& Schute.

Sartre, J. P. (2000). Nausea. Penguin Books.

Sartre, J. P. (2004). The transcendence of the ego: A sketch for a phenomenological description. Routledge.

Sartre, J. P. (2012). The imagination. Routledge.

Sartre, J. P. (2018). Being and nothingness: An essay in phenomenological ontology. Routledge.

Sparrow, T. (2014). The end of phenomenology: Metaphysics and the new realism. Edinburgh University Press.

Wahl, J. A. (1949). A short history of existentialism. Philosophical Library.

Publisher's Note Springer Nature remains neutral with regard to jurisdictional claims in published maps and institutional affiliations. 